\title{
Positron Emission Tomography Imaging of Hypoxia
}

\author{
Suzanne E. Lapi, PhD ${ }^{\mathrm{a}, \mathrm{a}}$, Thomas F. Voller ${ }^{\mathrm{b}}$, and Michael J. Welch, PhD $^{\mathrm{C}}$ \\ a Assistant Professor, Mallinckrodt Institute of Radiology, Washington University, St. Louis, MO \\ ${ }^{\mathrm{b}}$ Research Laboratory Manager, Mallinckrodt Institute of Radiology, Washington University, St. \\ Louis, MO \\ c Professor, Mallinckrodt Institute of Radiology, Washington University, St. Louis, MO
}

\section{Synopsis}

Hypoxia imaging has applications in functional recovery in ischemic events such as stroke and myocardial ischemia, but especially in tumors in which hypoxia can be predictive of treatment response and overall prognosis. Recently there has been development of imaging agents utilizing positron emission tomography for non-invasive imaging of hypoxia. Many of these PET agents have come to the forefront of hypoxia imaging. Halogenated PET nitroimidazole imaging agents labeled with ${ }^{18} \mathrm{~F}\left(\mathrm{t}_{1 / 2}=110 \mathrm{~m}\right)$ and ${ }^{124} \mathrm{I}\left(\mathrm{t}_{1 / 2}=110 \mathrm{~m}\right)$ have been under investigation for the last 25 years, with radiometal agents $\left({ }^{64} \mathrm{Cu}\right.$-ATSM) being developed more recently. This review focuses on these positron emission tomography imaging agents for hypoxia.

\section{Keywords \\ PET; hypoxia; ${ }^{18} \mathrm{~F}-\mathrm{MISO} ;{ }^{64} \mathrm{Cu}$-ATSM}

\section{Introduction}

Hypoxia in tissue is characterized as a lack of oxygen required for cells to function normally. It is usually defined as the oxygen tension at which the metabolic demand in stoma, endothelial cells and tumor cells exceeds the supply ${ }^{1}$. This imbalance between oxygen and delivery causes numerous downstream effects which has implications in various situations and disease states.

Hypoxia imaging has applications in functional recovery in ischemic events such as stroke and myocardial ischemia, but especially in tumors in which hypoxia can be predictive of treatment response and overall prognosis.

Hypoxia can occur in both heart and brain tissue following arterial occlusions and other events ${ }^{2}$. The heart is a very aerobic organ, consuming some $8-15 \mathrm{ml} \mathrm{O}_{2} / \mathrm{min} / 100 \mathrm{~g}$ tissue at rest and requires a constant supply of oxygen to maintain function and viability ${ }^{3}$. The heart

\footnotetext{
aCorresponding author for proofs and reprints: Suzanne E. Lapi, PhD, Mallinckrodt Institute of Radiology, Washington University, 510 South Kingshighway Blvd, St. Louis, MO, 63110, 314-362-4696, 314-362-9940 (fax), lapis@ mir.wustl.edu.

${ }^{b}$ Co-author: Thomas F. Voller, Mallinckrodt Institute of Radiology, Washington University, South Kingshighway Blvd, St. Louis, MO, 63110, 314-362-8433, 314-362-9940 (fax), vollert@wustl.edu

${ }^{\mathrm{c}}$ Co-author: Michael J. Welch, PhD, Mallinckrodt Institute of Radiology, Washington University, 510 South Kingshighway Blvd, St. Louis, MO, 63110, 314-362-8436, 314-362-8399 (fax), welchm@wustl.edu

Publisher's Disclaimer: This is a PDF file of an unedited manuscript that has been accepted for publication. As a service to our customers we are providing this early version of the manuscript. The manuscript will undergo copyediting, typesetting, and review of the resulting proof before it is published in its final citable form. Please note that during the production process errors may be discovered which could affect the content, and all legal disclaimers that apply to the journal pertain.
} 
can become exposed to ischemic conditions resulting from acute coronary events. Brief periods of ischemia ( $<20$ minutes) are reversible if followed by reperfusion ${ }^{4}$. If the duration of oxygen deprivation becomes longer, sections of the heart may become necrotic and non-viable4. During a stroke, blood flow to the brain is interrupted, and if this condition persists, brain function becomes impaired, sometimes irreversibly ${ }^{5}$. The longer the duration of hypoxia, the larger and more diffuse the area of the brain is affected. The high energy requirements of the brain render this organ particularly vulnerable to hypoxia 4 .

Hypoxia usually develops in tumors through a disruption in the vascular blood supply to the growing tumor mass. Tumor vessels are typically structurally and functionally abnormal compared to normal tissue, with the vasculature being characterized by vigorous proliferation which leads to structurally immature, defective and ineffective vessels. This results in vessels that are tortuous and leaky which can contribute to heterogeneity in blood flow and thus varied levels of oxygenation in tumors 6,7 . Blood flow in these abnormal vessels can vary considerably, from 0.01 to $2.0 \mathrm{ml} / \mathrm{g} / \mathrm{min}^{7}$, thus tumors can exhibit perfusion that is characteristic of a wide range of metabolic rates. In addition to the abnormal vasculature, fluid accumulating in the tumor matrix and the rapidly proliferating cancer cells themselves can cause high interstitial pressure which restricts and compresses the intratumor vessels causing collapse and reducing blood supply even further 7,8 . Hypoxia can also be caused by a deterioration of diffusion geometry within the tumor (again due to the abnormal blood vessels) or disease/therapy associated anemia which leads to a reduced oxygen transport by the blood $^{9}$. Thus hypoxia can result from diffusion and effusion issues and is usually the result of a combination of these problems1. There is evidence that tumors may consist of up to 50-60\% hypoxic or anoxic tissue heterogeneously distributed within the tumor mass with tumor to tumor variability greater than intra-tumor variability ${ }^{9}$. Clinically relevant hypoxia is detected in $50 \%$ of all solid tumors irrespective of size, stage, nodal status or other histopathological features with local recurrences typically having a higher hypoxic fraction than that of primary tumors ${ }^{7}$.

Hypoxia is associated with restrained proliferation, differentiation, necrosis or apoptosis and can lead to the development of a more aggressive cancer phenotype9. Hypoxia-induced proteome or genome changes may trigger mechanisms which enable cells to escape this "hostile" environment and hence favor unrestricted growth and mobility ${ }^{7}$. Lack of nutrients to the cells (due to reduced blood supply) in combination with hypoxia may also lead to these cellular changes thus causing progression, local growth and metastasis ${ }^{7}$. This situation can manifest as a higher rate of recurrence and metastasis and in the long term, decreased survival.

Hypoxia cells have been shown to have an increased resistance to radiotherapy. Radiotherapy is thought to rely mainly on the formation of free radicals which cause DNA damage, a mechanism which is enhanced by the presence of oxygen. Due to this oxygen enhancement effect, hypoxia can be a key factor is tumor development and therapy due to the increased radioresistance of hypoxic cells compared with normally oxygenated cells ${ }^{10}$. Early on, Gray et al determined the radiation dose required to achieve the same biologic effect is 2.8 to 3 times higher in the absence of oxygen then it's prescence ${ }^{11}$. Hypoxia is one of the major factors which negatively affects radiotherapy outcome ${ }^{1}$. Sustained hypoxia can also lead to alterations in the number of quiescent cells which leads to alterations in the response to radiation and chemotherapy ${ }^{7}$ as these therapies are primarily effective against rapidly proliferating cells ${ }^{12}$.

In patients with cervical carcinoma, tumor hypoxia is an important prognostic factor that predicts for decreased overall and disease-free survival. Moreover, hypoxic tumors are less responsive to irradiation than are normoxic tumors. A higher frequency of metastatic disease has been reported in patients with hypoxic soft tissue sarcomas and cervical cancer13, ${ }^{14}$. Brizel et al., have reported that a combination of radiotherapy and hyperthermia (to improve tumor 
oxygenation) in 38 patients with nonmetastatic high grade soft tissue sarcoma resulted in improvement of tumor oxygenation measured by polarographic oxygen electrodes and had an impact on treatment outcome ${ }^{14}$. They reported that patients with $<90 \%$ tumor necrosis in the resected specimen experienced longer disease free survival than those with $\geqq 90 \%$ necrosis. Höckel et al have studied 103 patients with advanced cervical cancer ${ }^{13}$. In cervical cancer, the oxygen status of the tumor was measured by invasive oxygen electrodes was noted to be the single most important prognostic factor. Patients with hypoxic cervical tumors had significantly worse disease-free survival and overall survival compared with nonhypoxic tumors. The poor outcomes in patients with hypoxic tumors was due to locoregional failure, irrespective of the mode of therapy (surgery or radiation) applied as primary treatment ${ }^{13}$.

Direct correlations have been made between imaging protocols and $\mathrm{PO}_{2}$ measurements taken with an Eppendorf pO2 hypoximeter which measures oxygen tensions using a polargraphic oxygen microelectrode. This direct real-time measurement of oxygen tension in tissues provided the first concrete evidence that intratumoral oxygen tension was indicative of survival in human cancers ${ }^{13}$. This method of oxygen measurement has demonstrated the clinical relevance of tumor hypoxia, although this methodology is limited by its invasiveness and is feasible only for superficial or easily accessible tumors ${ }^{15}$ and can also yield variable results due to sampling errors. In addition, the pO2 electrode only measures average oxygen tension and thus does not distinguish necrotic tissue from hypoxic but viable tissue which is a disadvantage for this technique ${ }^{13}$.

Noninvasive imaging protocols for the detection of hypoxia have been developed for Magnetic Resonance (MR). These techniques can be based on endogenous or exogenous contrast agents and can include Electron Paramagnetic Resonance (EPR)16, 17, Magnetic Resonance Spectroscopy (MRS) ${ }^{18}$, and Blood oxygen-dependent level (BOLD) imaging 19, 20. EPR relies on the injections of free radical contrast agents which reflect the absolute oxygen tension present in the tissue ${ }^{17}$. Although hypoxia cannot be directly detected by MRS, physiological conditions (uptake of binding markers) associated with the lack of oxygenation can be detected, usually by ${ }^{19} \mathrm{~F}$ MRS. The patient is injected with perfluorocarbons to measure oxygen tension. This technique relies on the change in the relaxation rate of the ${ }^{19} \mathrm{~F}$ being enhanced in direct proportion to the $\mathrm{O}_{2}$ concentration21, however these relaxation rates may depend on other physiological factors present in the tissue. Magnetic Resonance Imaging (MRI) can be used to detect paramagnetic deoxyhemoglobin distinctly from oxyhemoglobin and thus obtains a measure of blood oxygenation ${ }^{20}$. This technique is known as Blood Oxygen Level Dependent (BOLD) imaging and has been used to indirectly measure oxygen levels in animal20 and human22 tumors. A disadvantage of this technique is the inability to separate confounding effects related to blood flow heterogeneity 12 which is likely to be present in hypoxic tissue. Despite the development of these techniques, studies in humans with MR are limited ${ }^{12}$.

Recently there has been development of imaging agents utilizing positron emission tomography (PET) and single photon emission computed tomography (SPECT agents). Despite the wider availability of SPECT, many PET agents have come to the forefront of hypoxia imaging. Halogenated PET nitroimidazole imaging agents labeled with ${ }^{18} \mathrm{~F}\left(\mathrm{t}_{1 / 2}=110\right.$ $\mathrm{m})$ and ${ }^{124} \mathrm{I}\left(\mathrm{t}_{1 / 2}=110 \mathrm{~m}\right)$ have been under investigation for the last 25 years, with radiometal agents $\left({ }^{64} \mathrm{Cu}\right.$-ATSM) being developed more recently. The structures of several of these agents are shown in Figure 1. With the use of these specific hypoxia tracers, PET can be used for assessment and quantification of tumor hypoxia in a non-invasive manner. This method has potential for determination of the intratumor distribution of regional tumor hypoxia and thus may be used to select patients for hypoxia therapies. This review focuses on these positron emission tomography imaging agents for hypoxia. 


\section{Radiolabled 2-Nitroimidazoles as Markers for Hypoxia}

Nitroimidazoles were first proposed as reducible hypoxia markers in $1979^{23}$. These compounds enter cells by passive diffusion and undergo reduction forming a reactive intermediate species. In the presence of oxygen the molecule is reoxidized and the nitroimidazole diffuses back out of the cell, but under hypoxic conditions further reduction occurs, forming covalent bonds with intracellular macromolecules, thus trapping the compound inside the cell ${ }^{24}$. This mechanism is shown in Figure 2. Since the rate of uptake is strictly dependent on the oxygen concentration in the cell, correlations can be made between tracer concentration and hypoxia conditions. There are several fluorinated and iodinated agents that have been developed based on the nitroimidazole basic structure.

\section{$\left[{ }^{18}\right.$ F]fluoromisonidazole (FMISO)}

${ }^{18} \mathrm{~F}$-labeled misonidazole was proposed as a radioactive derivative of the nitroimidazoles in $1984{ }^{25},{ }^{26}$. Over the last decade $\left[{ }^{18} \mathrm{~F}\right] \mathrm{FMISO}$ has been studied as a PET agent for imaging hypoxia and to date, $\left[{ }^{18} \mathrm{~F}\right] \mathrm{FMISO}$ is currently the most widely used PET agent for mapping regional hypoxia and is generally considered to be the gold standard for PET hypoxia imaging. It has been shown to be retained in hypoxic cells both in vivo and in vitro.

In patients, time activity curves of this agent have shown that FMISO in normal tissue equilibrates with plasma levels within 30 minutes but is selectively retained in hypoxic tissue for up to 2.5 hours $^{27}$. Imaging protocols are typically 20-30 minutes and start from 75-150 minutes after injection of the radiotracer ${ }^{28}$. A typical threshold of tumor to plasma ratio of 1.4 at 2 hours post injection can be consider to be indicative of hypoxia ${ }^{27}$. This agent is metabolized by the liver and excreted through the kidneys and bladder. Organ doses for $\left[{ }^{18} \mathrm{~F}\right] \mathrm{FMISO}$ are comparable with other commonly performed nuclear medicine scans and indicate that the potential radiation risk associated with a $\left[{ }^{18} \mathrm{~F}\right] \mathrm{FMISO}$ scan is within generally accepted limits. The radiation exposure for an $\left[{ }^{18} \mathrm{~F}\right] \mathrm{FMISO}$ scan is equal to or lower than other radiopharmaceuticals ${ }^{29}$.

It has been shown that significant $\left[{ }^{18} \mathrm{~F}\right] \mathrm{FMISO}$ uptake requires a hypoxic level of $<10$ $\mathrm{mmHg}^{27}$. However, unlike the $\mathrm{pO} 2$ measurements FMISO is only sensitive to the presence of hypoxia in viable cells ${ }^{28}$ which may be advantageous for in vivo imaging in human subjects.

$\left[{ }^{18} \mathrm{~F}\right] \mathrm{FMISO}$ has been used in numerous oncology clinical studies including gliomas ${ }^{8}$, head and neck cancer ${ }^{30}$, and non small cell lung cancer. In an early study involving patient with malignant glioma, a feasibility study demonstrated the use of FMISO to detect hypoxia in the brain in vivo ${ }^{31}$. $\left[{ }^{18} \mathrm{~F}\right] \mathrm{FMISO}$ uptake has also been observed in the brain indicating that it is freely diffusible across the blood brain barrier.

$\left[{ }^{18} \mathrm{~F}\right]$ FMISO uptake has been correlated with low prognosis in both head and neck cancer and glioblastoma multiforme ${ }^{30,32}$. In patients with head and neck cancer a clear difference in $\left[{ }^{18} \mathrm{~F}\right] \mathrm{FMISO}$ uptake kinetics was observed in patients that responded to radiation therapy compared to non-responders ${ }^{30}$. Although $\left[{ }^{18} \mathrm{~F}\right] \mathrm{FMISO}$ uptake varied widely between patients and considerably between different parts of tumors, patients that were non-responsive to radiation therapy generally displayed higher levels of $\left[{ }^{18} \mathrm{~F}\right] \mathrm{FMISO}$ accumulation. Nonresponders also showed initially low perfusion of the tracers followed by accumulation indicating hypoxia, while responders showed high perfusion followed by rapid washout indicating well oxygenated, viable tumor tissue ${ }^{30}$. In this study no pattern was observed in patients with non-small cell lung cancer indicating that the choice of hypoxia imaging agent should be dependent on tumor type. In glioblastoma multiforme patients, both the volume and intensity of hypoxia as determined by $\left[{ }^{18} \mathrm{~F}\right] \mathrm{FMISO}$ scans before radiotherapy was strongly correlated with shortened time to progression and survival ${ }^{32}$. 
One study concluded that $\left[{ }^{18} \mathrm{~F}\right] \mathrm{FMISO}$ was not suitable for detection of tumor hypoxia in a variety of soft tissue tumors with no correlation found between hypoxic tumors (as determined by $\mathrm{O}_{2}$ electrode measurements) and those displaying enhanced $\left[{ }^{18} \mathrm{~F}\right] \mathrm{FMISO}$ uptake ${ }^{33}$. The authors of the publication with these negative $\left[{ }^{18} \mathrm{~F}\right] \mathrm{FMISO}$ findings speculate that the low uptake of FMISO in the tumors could be due to large amounts of necrosis in the soft tissue tumors and/or tumor heterogenity ${ }^{33}$ but further studies are warranted to determine the validity of $\left[{ }^{18} \mathrm{~F}\right] \mathrm{FMISO}$ in ascertaining the presence of hypoxia in soft tissue tumors.

Because of high lipophilicity, and slow kinetics of this tracer long imaging times are required and high contrast images are not typical with this agent (tumor to blood ratio >1.2). The slow washout of this tracer leading to a delay time of two hours required after injection to allow for clearance of the tracer from normal background tissues delays imaging and can result in poor statistics and images of limited quality ${ }^{34}$.

\section{$\left[{ }^{18} \mathrm{~F}\right]$ fluoroazomycin arabinoside (FAZA) and $\left[{ }^{124} \mathrm{I}\right]$ iodoazomycin arabinoside (IAZA)}

$\left[{ }^{18} \mathrm{~F}\right]$ fluoroazomycin arabinoside (FAZA) has been recently shown to have superior pharmacokinetics than $\left[{ }^{18} \mathrm{~F}\right] \mathrm{FMISO}$ primarily due to faster clearance from normal tissues resulting in higher tumor to background ratios ${ }^{35}$. This is due to increased lipophilicity of $\left[{ }^{18} \mathrm{~F}\right] \mathrm{FAZA}$ as compared to $\left[{ }^{18} \mathrm{~F}\right] \mathrm{FMISO}$. $\left[{ }^{18} \mathrm{~F}\right] \mathrm{FAZA}$ diffusion into cells is also faster, making it more readily available for reductive retention in hypoxia cells ${ }^{36}$. Tumor uptake of $\left[{ }^{18} \mathrm{~F}\right]$ FMISO in mice bearing human squamous cell carcinoma xenografts was approximately two times higher than for $\left[{ }^{18} \mathrm{~F}\right] \mathrm{FAZA}$ but tumor to blood ratios was significantly higher for $\left[{ }^{18} \mathrm{~F}\right]$ FAZA than $\left[{ }^{18} \mathrm{~F}\right] \mathrm{FMISO}$ due to slower clearance of $\left[{ }^{18} \mathrm{~F}\right] \mathrm{FMISO}$. In human studies, imaging with $\left[{ }^{18} \mathrm{~F}\right] \mathrm{FAZA}$ appears feasible in patients with head and neck cancer ${ }^{15}$. Image quality in these patients in a preliminary clinical study was determined to be adequate for clinical use. Tumor uptake was heterogeneous within individual tumors and between individuals suggesting large intertumor as well intratumor variability ${ }^{15}$. The authors from this study concluded that imaging at approximately two hours after radiotracer injection seemed to be a reasonable choice for ${ }^{18} \mathrm{~F}[\mathrm{FAZA}]$ tumor imaging as early timepoints were largely dependent on perfusion of the radiotracer into the tumor. The arbitrarily hypoxia threshold chosen (tumor to muscle ratio of 1.5 ) in this study was slightly higher that with $\left[{ }^{18} \mathrm{~F}\right] \mathrm{FMISO}$ (between 1.2 and 1.4 ) again possibly indicating superior kinetics ${ }^{15}$. However, more studies are required to fully ascertain the benefits of imaging with $\left[{ }^{18} \mathrm{~F}\right] \mathrm{FAZA}$ as opposed to $\left[{ }^{18} \mathrm{~F}\right] \mathrm{FMISO}$.

The iodinated analogue $\left[{ }^{124}\right.$ I]IAZA has also been prepared but imaging at later time points which were not possible with the fluorinated versions resulted in no advantage. Significant thyroid uptake was also reported in this study indicating possible deiodination of the $\left[{ }^{124} \mathrm{I}\right]$ IAZA $^{35}$.

\section{$\left[{ }^{124} I\right]$ - iodoazomycin galactopyranoside (IAZG)}

$\left[{ }^{124} \mathrm{I}\right] \mathrm{IAZG}$ was developed as a longer lived nitroimidazole PET radiotracer in order to obtain images at extended timepoints. Theoretically, in this manner images could be obtained after washout of the unbound tracer, thus yielding images with better contrast. [ ${ }^{124}$ I]IAZG uptake was shown to be consistent with independent measures of hypoxia in rat liver tumors ${ }^{37}$. In a comparison study between $\left[{ }^{18} \mathrm{~F}\right] \mathrm{FMISO}$ and $\left[{ }^{124} \mathrm{I}\right] \mathrm{IAZG}$ in rats bearing liver and peritoneal metastasis, both tracers were shown to accumulate in hypoxic tumor tissue. The two tracers also demonstrated similar tumor to background ratios although the optimal imaging time differed ( 3 hours for $\left[{ }^{18} \mathrm{~F}\right] \mathrm{FMISO}$ and 6 hours for $\left.\left[{ }^{124} \mathrm{I}\right] \mathrm{IAZG}\right){ }^{38}$. However, the $\left[{ }^{18} \mathrm{~F}\right] \mathrm{FMISO}$ agent yielded higher quality scans as the absolute concentration of the tracer was higher in the tumor and thus higher counting statistics were obtained. The difference in kinetic behavior between these two molecules may be attributed to the difference in lipophilicity of these two tracers. The authors suggest that deiodination of the $\left[{ }^{124} \mathrm{I}\right] \mathrm{IAZG}$ compound may also be 
responsible for the varied biodistribution but as thyroid uptake in the animals in this study was not reported it is difficult to determine ${ }^{38}$. A similar PET imaging agent, $\left[{ }^{124} \mathrm{I}\right]$ - iodoazomycin galactoside, in another study by the same group was shown to have high tumor to whole body ratios in both hypoxic fibrosarcoma and breast cancer models ${ }^{39}$. Comparisons with $\left[{ }^{18} \mathrm{~F}\right]$ FMISO showed optimal imaging at later time points ( 24 hours post injection vs 3 hours post injection for $\left.\left[{ }^{18} \mathrm{~F}\right] \mathrm{FMISO}\right)$ and higher tumor to normal tissue ratios were obtained. Higher absolute values of tracer accumulation were also obtained with [ $\left.{ }^{124} \mathrm{I}\right]$ - iodoazomycin galactoside (17\% as compared to $5-10 \%$ for $\left.\left[{ }^{18} \mathrm{~F}\right] \mathrm{FMISO}\right)^{39}$. Considerable deiodination was observed in vivo with this tracer as observed by the amount of radioactivity present in the thyroid in the animals. This data reinforces the notion that hypoxia agent selection may need to be tumor specific.

\section{$\left[{ }^{18} \mathrm{~F}\right] 1$-(2-fluoro-1-[hydroxymethyl]ethoxy)methyl-2-nitroimidazole (FRP170)}

RP170 was recently developed as a new 2-nitroimidazole analog with a hydrophilic side chain in attempts to increase the target to background ratios obtained with $\left[{ }^{18} \mathrm{~F}\right] \mathrm{FMISO}$.

Radiofluorination of this compound yields $\left[{ }^{18} \mathrm{~F}\right] \mathrm{FRP} 170$ which would be expected to yield superior images are earlier timepoints than $\left[{ }^{18} \mathrm{~F}\right] \mathrm{FMISO}^{40}$. A recent study in four healthy male volunteers and three lung cancer patients who underwent dynamic scanning after injection of $\left[{ }^{18}\right.$ F $]$ FRP170 revealed rapid elimination though the kidneys and liver with early uptake in lung cancer lesions ${ }^{40}$. Tumor uptake was clearly observed on all lung cancer subjects with contrast increasing over time. The authors concluded that $\left[{ }^{18} \mathrm{~F}\right] \mathrm{FRP} 170$ was almost equivalent to $\left[{ }^{18} \mathrm{~F}\right]$ FMISO although no match protocols were performed ${ }^{40}$.

The same group has also evaluated $\left[{ }^{18} \mathrm{~F}\right] \mathrm{FRP} 170$ in myocardial tissue in an animal model ${ }^{41}$. Visualization of ischemic but viable myocardial tissue was accomplished ex vivo with confirmation of the location of the damaged areas by histology. Further studies would be necessary to confirm the use of $\left[{ }^{18} \mathrm{~F}\right] \mathrm{FRP} 170$ for imaging hypoxic cardiac tissue.

\section{$\left.{ }^{18} \mathrm{~F}\right] 2-\left(2-n i t r o-{ }^{1} \mathrm{H}\right.$-imidazol-1-yl)-N-(2,2,3,3- pentafluoropropyl)-acetimide (EF5)}

EF5 was first developed as a biopsy based staining agents. A positron emitting version of this compound has been recently developed as an imaging agent of hypoxia. The enhanced lipophicity of this drug substantially increases its biological half-life and signal from hypoxiadependent metabolism ${ }^{42}$. EF5 is also reported to be the most stable of the 2-nitroimidazoles studies to date.

In a recent human trial with patients with newly diagnosed head and neck squamous cell carcinoma (HNSCC) the time course of $\left[{ }^{18} \mathrm{~F}\right] \mathrm{EF} 5$ was studied to determine the feasibility of this tracer as a hypoxia imaging agent ${ }^{43}$. The initial distribution of $\left[{ }^{18} \mathrm{~F}\right] \mathrm{EF} 5$ was found to be dominated by blood flow, whereas binding and uptake at later time points was found to be hypoxia specific. A tumor to muscle ratio of 1.5 was determined to be an appropriate threshold for the presence of clinically significant hypoxia. Additionally, increased $\left[{ }^{18} \mathrm{~F}\right] \mathrm{EF} 5$ uptake was found to be predictive higher grade tumor and of shorter time to metastasis in patients with soft tissue sarcomas ${ }^{44}$. This was also reported in patients with brain tumors ${ }^{45}$. The authors concluded that $\left[{ }^{18} \mathrm{~F}\right] \mathrm{EF} 5$ could be used to identify patients at high risk for metastases.

One possible drawback to EF5 is that its labeling chemistry is more complex than that for the other ${ }^{18}$ F-labeled agents thus possibly leading to reduced availability of this radiotracer ${ }^{46}$. 


\section{Copper-based Radiopharmaceuticals for Imaging Hypoxia $\left[{ }^{60,61,62,64} \mathrm{Cu}\right]$ Copper(II)-diacetyl-bis( $\mathrm{N}^{4}$-methylthiosemicarbazone (Cu-ATSM)}

Dithiosemicarbazones were discovered to possess antitumor properties in the 1960s. This led to the development of this class of ligands as radiopharmaceuticals due to the simplicity of the chemistry and the availability of copper positron emitting isotopes ${ }^{47}$. Cu-ATSM is a neutral lipophilic molecule which is highly membrane permeable and undergoes reduction and becomes trapped in the cell. This complex has been synthesized with a multitude of copper isotopes with varying half-lives, including ${ }^{60} \mathrm{Cu}\left(\mathrm{t}_{1 / 2}=23.7 \mathrm{~min}\right),{ }^{61} \mathrm{Cu}\left(\mathrm{t}_{1 / 2}=3.35 \mathrm{hr}\right),{ }^{62} \mathrm{Cu}$ $\left(\mathrm{t}_{1 / 2}=9.74 \mathrm{~min}\right)$ and ${ }^{64} \mathrm{Cu}\left(\mathrm{t}_{1 / 2}=12.7 \mathrm{hr}\right){ }^{47} \cdot{ }^{60} \mathrm{Cu},{ }^{61} \mathrm{Cu}$ and ${ }^{64} \mathrm{Cu}$ can be produced by proton bombardment of solid targets using a medical cyclotron, while ${ }^{62} \mathrm{Cu}$ is available from a generator similar to that used for ${ }^{99 \mathrm{~m}} \mathrm{Tc}^{47}$.

$\left[{ }^{64} \mathrm{Cu}\right]$ Copper(II)-diacetyl-bis( $\left(\mathrm{N}^{4}\right.$-methylthiosemicarbazone $\left({ }^{64} \mathrm{Cu}\right.$-ATSM $)$ was developed as an alternative to $\left[{ }^{18} \mathrm{~F}\right] \mathrm{FMISO} .\left[{ }^{64} \mathrm{Cu}\right]\left(\mathrm{t}_{1 / 2}=12.7 \mathrm{~h}, \beta^{+}=17.4 \%\right)$ can be produced in high specific activity in reliable quantities and the longer half-life allows for distribution to centers without a cyclotron over longer distances than possible with ${ }^{18} \mathrm{~F}$. This isotope also decays by $\beta^{-}$and can therefore have potential as both a diagnostic and therapeutic agent ${ }^{48}$.

The radiopharmaceutical ${ }^{62} \mathrm{Cu}$-ATSM was initially reported an agent for delineating hypoxic myocardial tissue in an isolated rat heart model ${ }^{49}$. The reduction of $\mathrm{Cu}(\mathrm{II})$ to $\mathrm{Cu}(\mathrm{I})$, which is the retention mechanism by which the copper is trapped in hypoxic tissue, was measured by electron spin resonance using non radioactive $\mathrm{Cu}$-ASTM and this study determined that the $\mathrm{Cu}-\mathrm{ATSM}$ was reduced in hypoxic but not in normal mitochondria. Rapid washout of this tracer from other tissues as well as favorable blood pool clearance may allow for screening for patients with myocardial hypoxia with this agent. Retention of the radiopharmaceutical was increased under hypoxic conditions and in this heart model, the ${ }^{62} \mathrm{Cu}$-ATSM retention was inversely correlated with ${ }^{201} \mathrm{Tl}$, a known blood flow marker ${ }^{49}$. Additional studies in several canine models determined quantitative and selective $\mathrm{Cu}$-ATSM radiotracer uptake in hypoxic myocardium ${ }^{50}$. This study was performed in order to determine the oxygen deprived myocardial state in both hypoxia and ischemia. The authors concluded that Cu-ATSM was an effective tracer for global hypoxia which was also useful in situations such as myocardial infarction where flow may be limited. This study also demonstrated that Cu-ATSM was not retained in necrotic tissue thus this tracer could differentiate between hypoxic, viable tissue and nonfunctional, dead, myocardial tissue ${ }^{50}$. In addition, these scans were performed only 20 minutes after tracer injection, thus showing differences between hypoxic and normal tissue can be rapidly obtained ${ }^{50}$. In a preliminary human patient study, ${ }^{62} \mathrm{Cu}$-ASTM PET imaging was performed in 7 patients with coronary heart disease. Increased uptake was observed in one patient with unstable angina ${ }^{51}$.

Yuan et al evaluated ${ }^{64} \mathrm{Cu}$-ATSM as a hypoxia agent by comparing autoradiography distributions of the radiotracers in animal studies with nonradioactive EF5, a validated hypoxia marker drug ${ }^{52}$. This group studied the uptake and immunohistochemistry in mammary adenocarcinomas, fibrosarcomas and gliomas. While they determined that high tumor to muscle ratios could be observed for the adenocarcinomas and gliomas, this was not the case for the fibrosarcomas ${ }^{52}$. This shows that although Cu-ATSM may be a valid hypoxia agent for some tumor types, this cannot be extrapolated to all tumors and hence this may not be a universal hypoxia marker.

The first report of Cu-ASTM in a human study was with ${ }^{62} \mathrm{Cu}-\mathrm{ATSM}$ in 2000 and was conducted in normal subjects and patients with lung cancer ${ }^{53}$. Intense uptake of the ${ }^{62} \mathrm{Cu}$ ATSM was observed in all lung cancer patients reaching a plateau within a few minutes after injections. The mean tumor to backgrounds ratio of ${ }^{62} \mathrm{Cu}$-ATSM was 3.00 with a maximum 
of $9.33^{53}$. The radiotracer cleared rapidly from the blood and lungs of all normal subjects. In addition to this a negative correlation was observed in three out of four patients between flow and flow-normalized ${ }^{62} \mathrm{Cu}$-ATSM uptake, indicating that ${ }^{62} \mathrm{Cu}$-ATSM uptake might be increased by low flow.

$\mathrm{Cu}$-ATSM has also been evaluated in patients with rectal ${ }^{54}$ and cervical cancer ${ }^{55}$. These were correlative studies designed to determine if uptake of ${ }^{60} \mathrm{Cu}$-ATSM was predictive of a response to therapy. In patients with rectal cancer a pilot study indicated that ${ }^{60} \mathrm{Cu}$-ATSM uptake may be predictive of survival but that further studies were needed to confirm this ${ }^{54}$. In a small study in cervical cancer patients the inter-patient ${ }^{60} \mathrm{Cu}$-ATSM uptake was variable and found to strongly correlate with response to therapy and overall survival ${ }^{55}$. A tumor to muscle ratio of 3.5 was determined to be an accurate cutoff for distinguishing patients who did and did not develop disease recurrence after radiation therapy. In addition this study determined that the prognostic information obtained from ${ }^{60} \mathrm{Cu}$-ATSM could not be derived from FDG-PET. Further studies comparing ${ }^{60} \mathrm{Cu}$-ATSM with ${ }^{64} \mathrm{Cu}$-ATSM in patients with cancer of the uterine cervix fount that patterns of these radiopharmaceuticals were similar and image quality of the ${ }^{64} \mathrm{Cu}$-ATSM was superior to the ${ }^{60} \mathrm{Cu}-\mathrm{ATSM}^{56}$. Representative images from this study are shown in Figure 3. The use of this longer lived analogue in this crossover study demonstrated the utility of ${ }^{64} \mathrm{Cu}$-ATSM, which would allow for production and shipping of this radiopharmaceutical to supply large multicenter trials.

Overall this agent shows rapid delineation of tumor hypoxia and higher tumor to background ratios ( $\gg 2.0)$ thus showing advantages over $\left[{ }^{18} \mathrm{~F}\right] \mathrm{FMISO}^{47}$. A current large scale clinical trial with this radiopharmaceutical may shed more light on the advantages of Cu-ATSM.

\section{Conclusion}

A recent review concluded "PET imaging with specific hypoxia tracers is becoming a must in radiation therapy planning" ${ }^{10}$. With the developments of new therapies in phase three clinical trials to overcome hypoxia in tumors, the testing of predictive assays that can identify patient populations that can benefit from these treatments is necessary57. In addition, it has been suggested that dynamic hypoxia measurements during oxygen-modifying treatments could aid in the determination of responding and non-responding patients ${ }^{1}$. Reduction of unnecessary treatments in non-responding patients could result in decreased side effects as well as the opportunity to modify the patient treatment regime. Assays are needed for prediction of patient outcome, and as treatment selection tool and for evaluation of treatment response. These techniques may be used to apply hypoxia-directed interventions such as intensity modulation radiation therapy (IMRT) and chemotherapy with hypoxia selective drugs such as tirapazamine ${ }^{12}$.

\section{References}

1. Ljungkvist ASE, Bussink J, Kaanders JHAM, et al. Dynamics of tumor hypoxia measured with bioreductive hypoxic cell markers. Radiation Research Feb;2007 167(2):127-145. [PubMed: 17390721]

2. Mathias CJ, Welch MJ, Kilbourn MR, et al. Radiolabeled hypoxic cell sensitizers: tracers for assessment of ischemia. Life Sci Jul 13;1987 41(2):199-206. [PubMed: 3600179]

3. Giordano FJ. Oxygen, oxidative stress, hypoxia, and heart failure. J Clin Invest Mar;2005 115(3):500508. [PubMed: 15765131]

4. Michiels C. Physiological and pathological responses to hypoxia. Am J Pathol Jun;2004 164(6):18751882. [PubMed: 15161623]

5. Won SJ, Kim DY, Gwag BJ. Cellular and molecular pathways of ischemic neuronal death. J Biochem Mol Biol Jan 31;2002 35(1):67-86. [PubMed: 16248972] 
6. Jain RK. Normalization of tumor vasculature: An emerging concept in antiangiogenic therapy. Science Jan 7;2005 307(5706):58-62. [PubMed: 15637262]

7. Vaupel P. Tumor microenvironmental physiology and its implications for radiation oncology. Seminars in Radiation Oncology Jul;2004 14(3):198-206. [PubMed: 15254862]

8. Padera TP, Stoll BR, Tooredman JB, et al. Cancer cells compress intratumour vessels. Nature Feb 19;2004 427(6976):695-695. [PubMed: 14973470]

9. Vaupel P, Mayer A. Hypoxia in cancer: significance and impact on clinical outcome. Cancer Metastasis Rev Jun;2007 26(2):225-239. [PubMed: 17440684]

10. Lucignani G. PET imaging with hypoxia tracers: a must in radiation therapy. Eur J Nucl Med Mol Imaging Apr;2008 35(4):838-842. [PubMed: 18264705]

11. Gray LH, Conger AD, Ebert M, et al. The concentration of oxygen dissolved in tissues at the time of irradiation as a factor in radiotherapy. Br J Radiol Dec;1953 26(312):638-648. [PubMed: 13106296]

12. Foo SS, Abbott DF, Lawrentschuk N, et al. Functional imaging of intratumoral hypoxia. Mol Imaging Biol Sep-Oct;2004 6(5):291-305. [PubMed: 15380739]

13. Hockel M, Knoop C, Schlenger K, et al. Intratumoral pO2 predicts survival in advanced cancer of the uterine cervix. Radiother Oncol Jan;1993 26(1):45-50. [PubMed: 8438086]

14. Brizel DM, Scully SP, Harrelson JM, et al. Tumor oxygenation predicts for the likelihood of distant metastases in human soft tissue sarcoma. Cancer Res Mar 1;1996 56(5):941-943. [PubMed: 8640781]

15. Souvatzoglou M, Grosu AL, Roper B, et al. Tumour hypoxia imaging with [18F]FAZA PET in head and neck cancer patients: a pilot study. Eur J Nucl Med Mol Imaging Oct;2007 34(10):1566-1575. [PubMed: 17447061]

16. Gallez B, Baudelet C, Jordan BF. Assessment of tumor oxygenation by electron paramagnetic resonance: principles and applications. NMR Biomed Aug;2004 17(5):240-262. [PubMed: 15366026]

17. Pan X, Xia D, Halpern H. Targeted-ROI imaging in electron paramagnetic resonance imaging. J Magn Reson Jul;2007 187(1):66-77. [PubMed: 17451981]

18. Kwock L, Gill M, McMurry HL, et al. Evaluation of a fluorinated 2-nitroimidazole binding to hypoxic cells in tumor-bearing rats by $19 \mathrm{~F}$ magnetic resonance spectroscopy and immunohistochemistry. Radiat Res Jan;1992 129(1):71-78. [PubMed: 1728059]

19. Landuyt W, Hermans R, Bosmans H, et al. BOLD contrast fMRI of whole rodent tumour during air or carbogen breathing using echo-planar imaging at 1.5 T. Eur Radiol 2001;11(11):2332-2340. [PubMed: 11702181]

20. Dunn JF, O'Hara JA, Zaim-Wadghiri Y, et al. Changes in oxygenation of intracranial tumors with carbogen: a BOLD MRI and EPR oximetry study. J Magn Reson Imaging Nov;2002 16(5):511-521. [PubMed: 12412027]

21. Clark LC Jr, Ackerman JL, Thomas SR, et al. Perfluorinated organic liquids and emulsions as biocompatible NMR imaging agents for 19F and dissolved oxygen. Adv Exp Med Biol 1984;180:835-845. [PubMed: 6534151]

22. Griffiths JR, Taylor NJ, Howe FA, et al. The response of human tumors to carbogen breathing, monitored by Gradient-Recalled Echo Magnetic Resonance Imaging. Int J Radiat Oncol Biol Phys Oct 1;1997 39(3):697-701. [PubMed: 9336152]

23. Chapman JD, Franko AJ, Sharplin J. A Marker for Hypoxic Cells in Tumors with Potential Clinical Applicability. British Journal of Cancer 1981;43(4):546-550. [PubMed: 7236492]

24. Whitmore GF, Varghese AJ. The Biological Properties of Reduced Nitroheterocyclics and Possible Underlying Biochemical-Mechanisms. Biochemical Pharmacology Jan 1;1986 35(1):97-103. [PubMed: 3510061]

25. Rajendran JG, Schwartz DL, O’Sullivan J, et al. Tumor hypoxia imaging with [F-18] fluoromisonidazole positron emission tomography in head and neck cancer. Clinical Cancer Research Sep 15;2006 12(18):5435-5441. [PubMed: 17000677]

26. Gronroos T, Eskola I, Lehtio K, et al. Pharmacokinetics of [F-18]FETNIM: A potential hypoxia marker for PET. Journal of Nuclear Medicine Sep;2001 42(9):1397-1404. [PubMed: 11535732]

27. Lee ST, Scott AM. Hypoxia positron emission tomography imaging with F-18-fluoromisonidazole. Seminars in Nuclear Medicine Nov;2007 37(6):451-461. [PubMed: 17920352] 
28. Padhani A. PET imaging of tumour hypoxia. Cancer Imaging 2006;6:S117-121. [PubMed: 17114063]

29. Krohn KA, Link JM, Mason RP. Molecular imaging of hypoxia. Journal of Nuclear Medicine Jun; 2008 49:129s-148s. [PubMed: 18523070]

30. Eschmann SM, Paulsen F, Reimold M, et al. Prognostic impact of hypoxia imaging with F-18misonidazole PET in non-small cell lung cancer and head and neck cancer before radiotherapy. Journal of Nuclear Medicine Feb;2005 46(2):253-260. [PubMed: 15695784]

31. Valk PE, Mathis CA, Prados MD, et al. Hypoxia in Human Gliomas - Demonstration by Pet with Fluorine-18-Fluoromisonidazole. Journal of Nuclear Medicine Dec;1992 33(12):2133-2137. [PubMed: 1334136]

32. Spence AM, Muzi M, Swanson KR, et al. Regional hypoxia in glioblastoma multiforme quantified with [18F]fluoromisonidazole positron emission tomography before radiotherapy: correlation with time to progression and survival. Clin Cancer Res May 1;2008 14(9):2623-2630. [PubMed: 18451225]

33. Bentzen L, Keiding S, Nordsmark M, et al. Tumour oxygenation assessed by F-18-fluoromisonidazole PET and polarographic needle electrodes in human soft tissue tumours. Radiotherapy and Oncology Jun;2003 67(3):339-344. [PubMed: 12865184]

34. Nunn A, Linder K, Strauss HW. Nitroimidazoles and Imaging Hypoxia. European Journal of Nuclear Medicine Mar;1995 22(3):265-280. [PubMed: 7789400]

35. Reischl G, Dorow DS, Cullinane C, et al. Imaging of tumor hypoxia with [I-124] IAZA in comparison with [F-18] FMISO and [F-18]FAZA - first small animal PET results. Journal of Pharmacy and Pharmaceutical Sciences Jun;2007 10(2):203-211. [PubMed: 17706178]

36. Kumar P, Stypinski D, Xia H, et al. Fluoroazomycin arabinoside (FAZA): Synthesis, H-2 and H-3labelling and preliminary biological evaluation of a novel 2-nitroimidazole marker of tissue hypoxia. Journal of Labelled Compounds \& Radiopharmaceuticals Jan;1999 42(1):3-16.

37. Riedl CC, Brader P, Zanzonico PB, et al. Imaging hypoxia in orthotopic rat liver tumors with iodine 124-labeled iodoazomycin galactopyranoside PET. Radiology Aug;2008 248(2):561-570. [PubMed: 18641253]

38. Riedl CC, Brader P, Zanzonico P, et al. Tumor hypoxia imaging in orthotopic liver tumors and peritoneal metastasis: a comparative study featuring dynamic F-18-MISO and I-124-IAZG PET in the same study cohort. European Journal of Nuclear Medicine and Molecular Imaging Jan;2008 35 (1):39-46. [PubMed: 17786438]

39. Zanzonico P, O’Donoghue J, Chapman JD, et al. Iodine-124-labeled iodo-azomycin-galactoside imaging of tumor hypoxia in mice with serial microPET scanning. European Journal of Nuclear Medicine and Molecular Imaging Jan;2004 31(1):117-128. [PubMed: 14523586]

40. Kaneta T, Takai Y, Iwata R, et al. Initial evaluation of dynamic human imaging using F-18-FRP170 as a new PET tracer for imaging hypoxia. Annals of Nuclear Medicine Feb;2007 21(2):101-107. [PubMed: 17424976]

41. Kaneta T, Takai Y, Kagaya Y, et al. Imaging of ischemic but viable myocardium using a new F-18labeled 2-nitroimidazole analog, F-18-FRP170. Journal of Nuclear Medicine Jan;2002 43(1):109_ 116. [PubMed: 11801713]

42. Koch CJ, Hahn SM, Rockwell K, et al. Pharmacokinetics of EF5 [2-(2-nitro-1-H-imidazol-1-yl)-N(2,2,3,3,3-pentafluoropropyl) acetamide] in human patients: implications for hypoxia measurements in vivo by 2-nitrolmidazoles. Cancer Chemotherapy and Pharmacology Sep;2001 48(3):177-187. [PubMed: 11592338]

43. Komar G, Seppanen M, Eskola O, et al. F-18-EF5: A New PET Tracer for Imaging Hypoxia in Head and Neck Cancer. Journal of Nuclear Medicine Dec;2008 49(12):1944-1951. [PubMed: 18997048]

44. Evans SM, Fraker D, Hahn SM, et al. EF5 binding and clinical outcome in human soft tissue sarcomas. International Journal of Radiation Oncology Biology Physics Mar 1;2006 64(3):922-927.

45. Evans SM, Judy KD, Dunphy I, et al. Comparative measurements of hypoxia in human brain tumors using needle electrodes and EF5 binding. Cancer Research Mar 1;2004 64(5):1886-1892. [PubMed: 14996753] 
46. Dolbier WR, Li AR, Koch CJ, et al. [F-18]-EF5, a marker for PET detection of hypoxia: synthesis of precursor and a new fluorination procedure. Applied Radiation and Isotopes Jan;2001 54(1):7380. [PubMed: 11144255]

47. Vavere AL, Lewis JS. Cu-ATSM: A radiopharmaceutical for the PET imaging of hypoxia. Dalton Transactions 2007;4:4893-4902. [PubMed: 17992274]

48. Blower PJ, Lewis JS, Zweit J. Copper radionuclides and radiopharmaceuticals in nuclear medicine. Nuclear Medicine and Biology Nov;1996 23(8):957-980. [PubMed: 9004284]

49. Fujibayashi Y, Taniuchi H, et al. Copper-62-ATSM: A new hypoxia imaging agent with high membrane permeability and low redox potential. Journal of Nuclear Medicine Jul;1997 38(7):11551160. [PubMed: 9225812]

50. Lewis JS, Herrero P, Sharp TL, et al. Delineation of hypoxia in canine myocardium using PET and copper(II)-diacetyl-bis(N-4-methylthiosemicarbazone). Journal of Nuclear Medicine Nov;2002 43 (11):1557-1569. [PubMed: 12411560]

51. Takahashi N, Fujibayashi Y, Yonekura Y, et al. Copper-62 ATSM as a hypoxic tissue tracer in myocardial ischemia. Annals of Nuclear Medicine Jun;2001 15(3):293-296. [PubMed: 11545205]

52. Yuan H, Schroeder T, Bowsher JE, et al. Intertumoral differences in hypoxia selectivity of the PET imaging agent 64Cu(II)-diacetyl-bis(N4-methylthiosemicarbazone). J Nucl Med Jun;2006 47(6): 989-998. [PubMed: 16741309]

53. Takahashi N, Fujibayashi Y, Yonekura Y, et al. Evaluation of 62Cu labeled diacetyl-bis(N4methylthiosemicarbazone) as a hypoxic tissue tracer in patients with lung cancer. Ann Nucl Med Oct;2000 14(5):323-328. [PubMed: 11108159]

54. Dietz DW, Dehdashti F, Grigsby PW, et al. Tumor hypoxia detected by positron emission tomography with $60 \mathrm{Cu}-\mathrm{ATSM}$ as a predictor of response and survival in patients undergoing Neoadjuvant chemoradiotherapy for rectal carcinoma: a pilot study. Dis Colon Rectum Nov;2008 51(11):16411648. [PubMed: 18682881]

55. Dehdashti F, Grigsby PW, Mintun MA, et al. Assessing tumor hypoxia in cervical cancer by positron emission tomography with $60 \mathrm{Cu}$-ATSM: relationship to therapeutic response-a preliminary report. Int J Radiat Oncol Biol Phys Apr 1;2003 55(5):1233-1238. [PubMed: 12654432]

56. Lewis JS, Laforest R, Dehdashti F, et al. An imaging comparison of 64Cu-ATSM and 60Cu-ATSM in cancer of the uterine cervix. J Nucl Med Jul;2008 49(7):1177-1182. [PubMed: 18552145]

57. Kaanders JH, Bussink J, van der Kogel AJ. Clinical studies of hypoxia modification in radiotherapy. Semin Radiat Oncol Jul;2004 14(3):233-240. [PubMed: 15254866] 


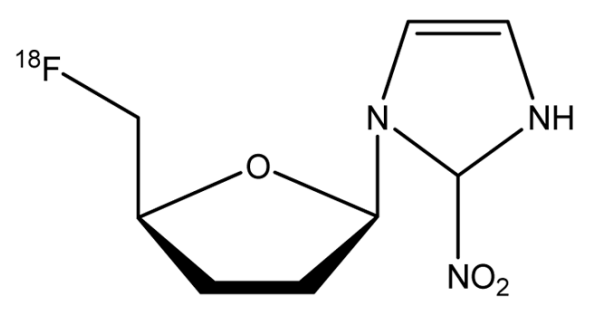

$\left[{ }^{18} \mathrm{~F}\right] \mathrm{FAZA}$
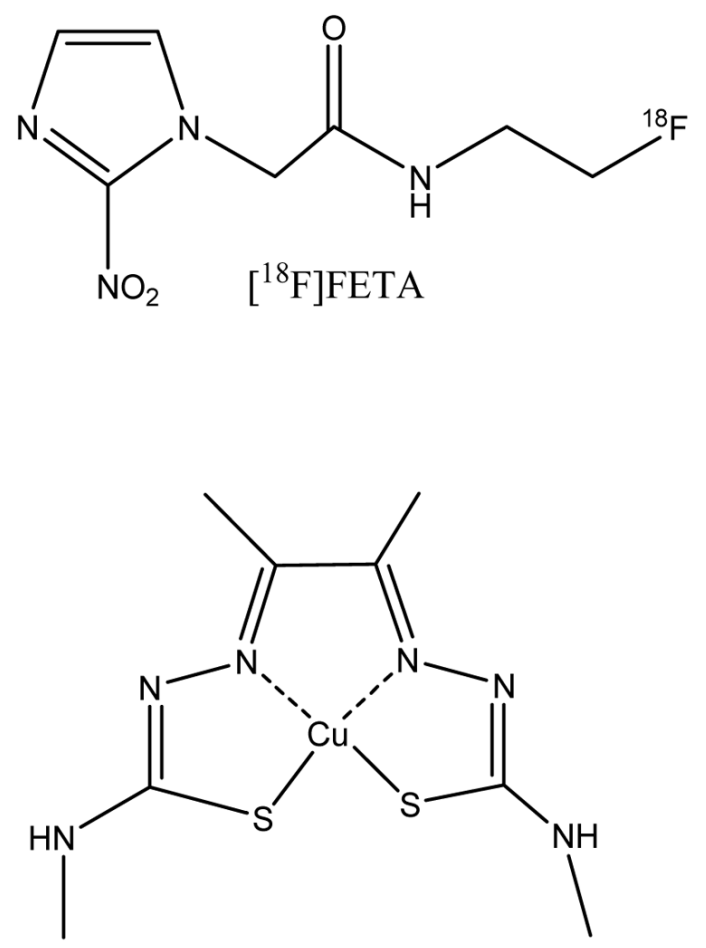

Cu-ATSM



$\left[{ }^{18} \mathrm{~F}\right] \mathrm{FETNIM}$

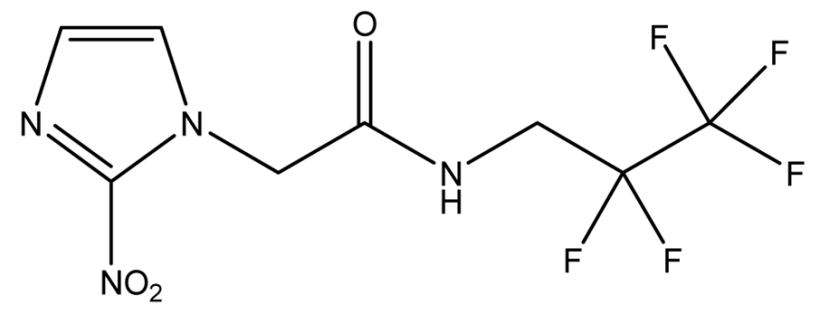

$\left[{ }^{18} \mathrm{~F}\right] \mathrm{EF} 5$

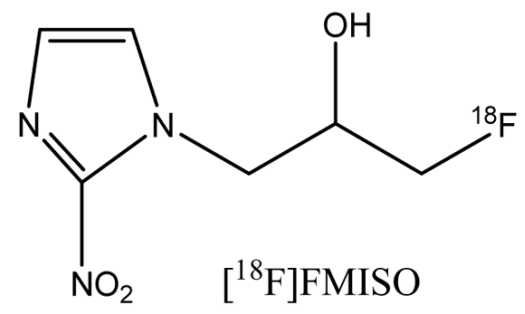

Figure 1.

Structure of hypoxia PET imaging agents 


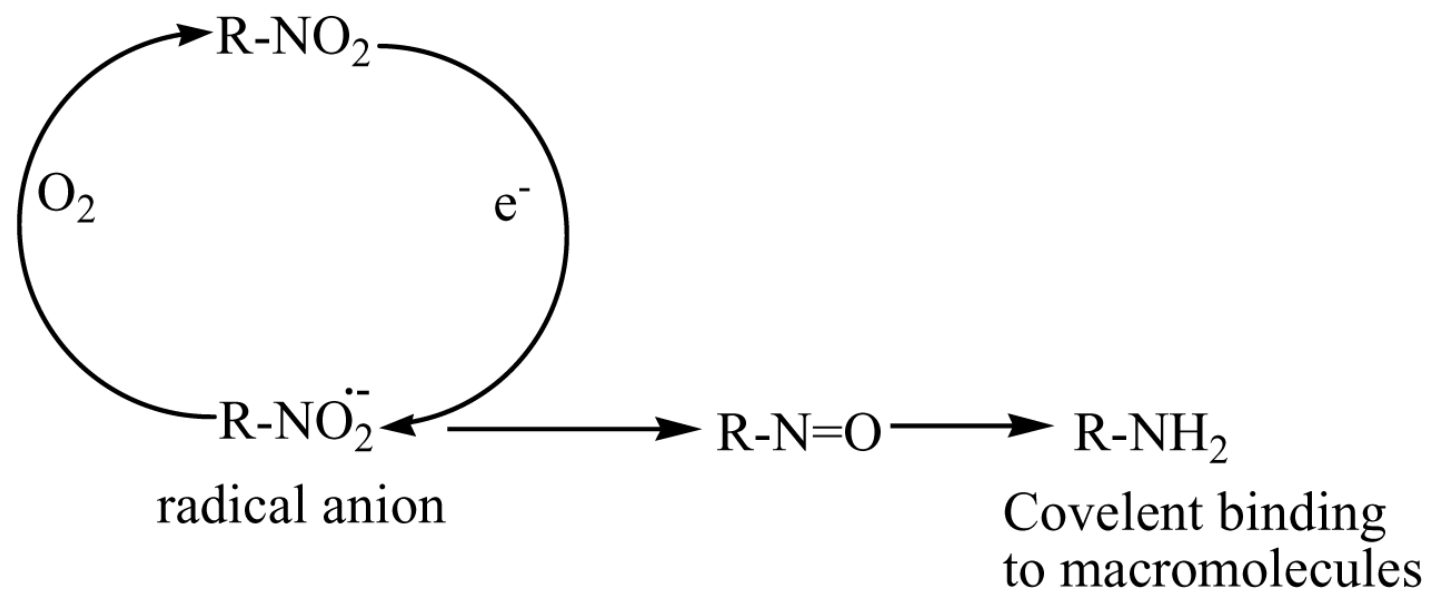

Figure 2.

Mechanism of Nitroimidazole retention in hypoxic tissue 


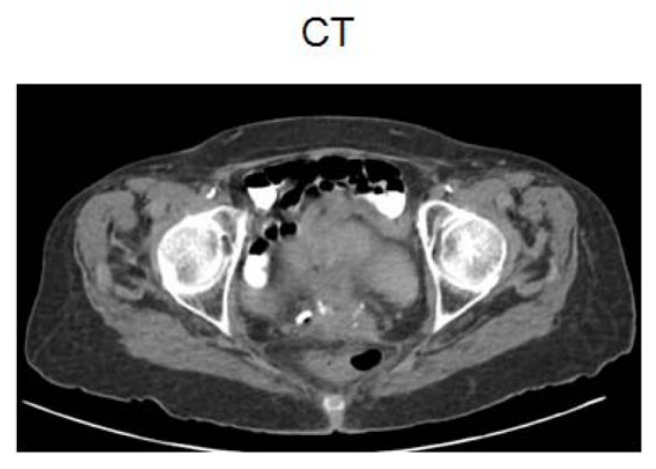

${ }^{60} \mathrm{Cu}$-ATSM-PET

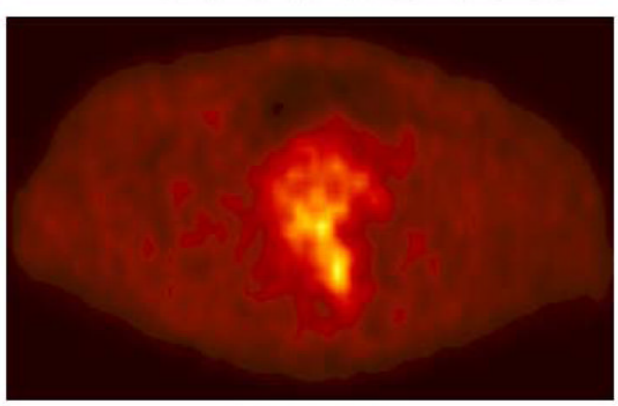

$\mathrm{T} / \mathrm{M}=\mathbf{5 . 0}$
FDG-PET

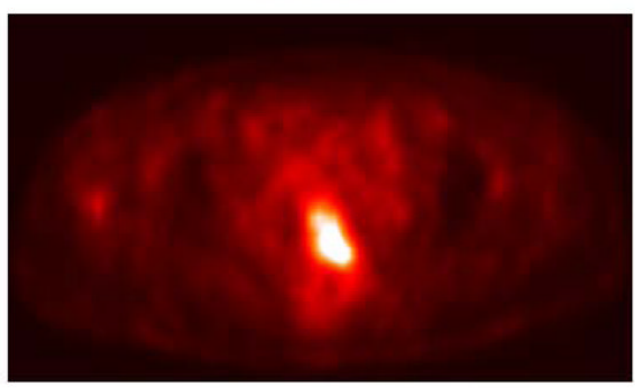

${ }^{64} \mathrm{Cu}$-ATSM-PET

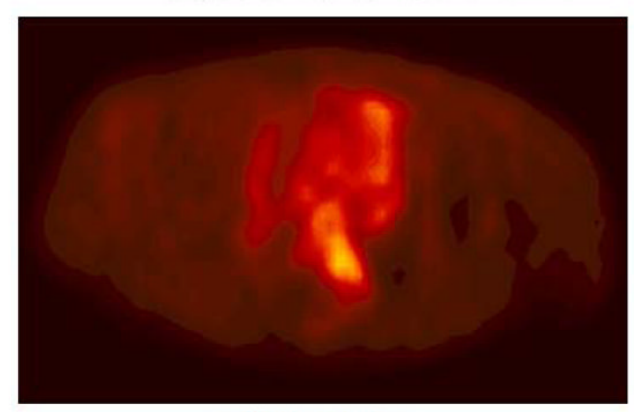

$\mathrm{T} / \mathrm{M}=\mathbf{5 . 8}$

Figure 3.

Comparison of ${ }^{60} \mathrm{Cu}-\mathrm{ATSM}$ and ${ }^{64} \mathrm{Cu}-\mathrm{ATSM}$ 